\title{
IN VITRO EFFECT OF Chloroprocta SP. MAGGOTS SECRETION ON Staphylococcus epidermidis BIOFILM AND THE EXPRESSION LEVEL icaA OF GENE
}

\author{
Dwi Utami Anjarwati ${ }^{1}{ }^{*}$ Setiawati $^{2}$, Mujahidah ${ }^{3}$, Rebriarina Hapsari ${ }^{3}$, \\ Titik Nuryastuti ${ }^{4}$
}

\begin{abstract}
${ }^{1}$ Lab. of Microbiology , Faculty Medicine and Health Science. Jendral Soedirman University. Jl. Dr. Suparno-Purwokerto, 53122

${ }^{2}$ Lab. of Farmacology Faculty Medicine and Health Science of Jendral Soedirman University. Jl. Dr. SuparnoPurwokerto, 53122 ${ }^{3}$ Dept. of Microbiology Faculty of Medicine of Diponegoro University Kariadi Hospital.

Jl. Doktor Soetomo No.14, 50244, Indonesia ${ }^{4}$ Dept. of Microbiology Faculty Medicine. Gadjah Mada University.

Yogyakarta, Sekip Utara 55281, Indonesia
\end{abstract}

Submitted: $20-12-2013$

Revised: 23-01-2014

Accepted: 03-03-2014

*Corresponding author Dwi Utami Anjarwati

Email :

dzikrarana@gmail.com

\section{INTRODUCTION}

S. epidermidis is a major pathogen of medical device-associated infections. (Rupp and Archer, 1994). Polysaccharide intercellular adhesin (PIA) is the main virulence factor of $S$. epidermidis biofilm. Polysaccharide intercellular adhesin play a significant role in biofilm formation, especially in initial bacterial adherence and intracelullar adhesion (Mack et al., 1996; O'Gara and Humphreys, 2001). Polysaccharide intercellular adhesin is synthesized by enzymes encoded genes icaA, ica $\mathrm{D}, \quad i c a \mathrm{~B}$, ica $\mathrm{C}$ genes. icaD was always expressed in biofilm-production strains and non-biofilm production strains, meanwhile ica $A$ is only expressed on biofilm-production strains (Cafiso et al., 2004).

Biofilm-producing bacteria show 101,000-fold less susceptible to many antimicrobial agents than planktonic cells (Davies, 2003). The emergence of antibiotic resistant of biofilm-producing bacterial has caused a resurgence in the research of component to enhance the effect of conventional antibiotics. Subinhibitory concentrations of some antibiotics can influence the expression of significant bacterial virulence factors. The expression of ica operon can be highly enhanced by combination of streptogramin and quinupristin-dalfopristin and by tetracycline (Rachid et al., 2000). 
Previous study has evaluated the effect of green flies secretion, Lucilia sericata, maggots on nascent biofilm formation and the disruption of pre-formed biofilms of $S$. epidermidis strains in accordance to the polysaccharide intercellular adhesin or the accumulation of associated protein mechanisms for biofilm accumulation (Harris et al., 2009). Cbloroprocta sp. is one of green flies of the family Calliphoridae found predominantly in Semarang, Central Java. Therefore, the present study was aim to evaluate in vitro effect of Chloroprocta sp. maggots secretion at low concentration on the formation of $S$. epidermidis biofilm (phenotype) and the expression level of icaA gene (genotype). The data obtained were used for evaluating the mechanisms of maggots excretion/ secretion in eradicating bacterials biofilm at phenotype and genotype levels.

\section{MATERIAL AND METHODS Larvae and collection of maggots excretion/ secretion}

Late second or early third instar larva of Chloroprocta sp. maggots were obtained from the Laboratory of Nutritional Biochemistry of Agriculture and Husbandry, Faculty of Diponegoro University, Semarang. Excretion/ secretion were collected from these maggots. Briefly, maggots were transferred to sterile tubes to provide a density of 100 maggots in $200 \mu \mathrm{L}$ of phosphate buffer saline and incubated in the dark at room temperature $\left(25^{\circ} \mathrm{C}\right)$ for one hour. The obtained liquid was transferred to another tube and sterilized (Arora et al., 2010).

\section{Bacterial strains}

The bacterial strains used in this study were biofilm-positive and icaA-positive $S$. epidermidis 294, 734, 169; while the clinically isolated negative control of biofilm is $S$. epidermidis ATCC12228. S. epidermidis 294 is a clinical isolate from the Department of Microbiology, Faculty of Medical Diponegoro University-Kariadi Hospital Semarang. Meanwhile, the other strains were the collection of the Department of Microbiology Faculty of Medicine, Gadjah Mada University. S. epidermidis strains were cultured in Trypticase Soy Broth (TSB) at $37^{\circ} \mathrm{C}$ for $24 \mathrm{~h}$ (overnight culture).

\section{Biofilm assay}

The biofilm phenotype isolate of $S$. epidermidis was determined with a microtiter plate biofilm assay using 96-well tissue culture plates to measure the attachment and the accumulation on the plastic surface, as described previously with modification (Merrit et al., 2011). Briefly, overnight cultures of the strains in Trypticase Soy Broth were diluted 1:100 in fresh Trypticase Soy Broth and $20 \mu \mathrm{L}$ cultures were inoculated into $200 \mu \mathrm{L}$ Trypticase Soy Broth in each well. After $24 \mathrm{~h}$ of incubation at $37^{\circ} \mathrm{C}$, the plates were washed with phospat buffer saline and the adherent bacteria were stained with $1 \%$ crystal violet. The absorbance at $595 \mathrm{~nm}\left(\mathrm{~A}_{595}\right)$ of the stained adherent bacterial films was quantified with microplate reader (Biorad). To quantify the effect of maggots secretion concentration on $S$. epidermidis biofilm formation, the biofilm assays were performed using secrete dilutions: $10 \%, 20 \%$, $30 \%, 40 \%, 50 \%, 60 \%, 70 \%, 80 \%, 90 \%, 100 \%$ and no excretion/secretion was added to the control wells. Briefly, 96 wells of tissue culture plates were filled with $100 \mu \mathrm{L}$ Trypticase Soy Broth containing maggots secretion from $0 \%$ to $100 \%$ for each well as mentioned above. All experiments were performed three times. $S$. epidermidis ATCC12228 was used for negative biofilm control.

To determine the lowest concentration of maggots secretion enhancing S. epidermidis biofilm formation, the biofilm assays were performed using a series of maggots secretion dilutions $1 / 2$ fold from $5 \%$ to $0.0045 \%$ and no maggots secretion was added to the control wells. Experiments were tested in duplo. Strain with higher optical density than the negative control after administration of maggots secretion (0 to $100 \%$ ) was examined (734). $S$. epidermidis ATCC12228 was used for negative control.

\section{The expression level of icaA gene}

Total RNA was isolated from $24 \mathrm{~h}$ biofilm-producing bacteria cultures with and without $5 \%$ maggots secretion in 12 -well tissue culture plate as described previously with some modification (Nuryastuti et al., 2009). Briefly, after suspending, the biofilm-producing bacteria were pelleted by centrifugation and frozen at $-56^{\circ} \mathrm{C}$. The samples were thawed 
slowly on ice and resuspended in $100 \mu \mathrm{L}$ diethylpyrocarbonate (DEPC)-treated water. The total RNA was isolated using the ambion purelink RNA mini kit according to the manufacture's instructions. Approximately, 11 $\mu \mathrm{L}$ of $\mathrm{RNA}$ sample was used for cDNA synthesis according to the manufacture's instructions (Transcriptor First Strand cDNA synthesis kit). Real TimePCR was performed. The expression level of icaA gene was analyzed by Real TimePCR in a LightCycler method with untreated biofilms as controls and $\mathrm{gyrB}$ as the reference. Primer used for LightCycler metode were: icaA-1 forward (sequence GAAGTT CTGATAATACTGCTG; icaA-1 reverse (GATG CTTGTTTGATTCCCTC), 129 bp in size. Reference primers were gyrB-3 forward (GGAGGT AAATTCGGAGGT) and gyrB-3 reverse CTTGATGATAAATCGTGCCA), 129 bp in size.

\section{Biofilm-producing bacteria susceptibi- lity to maggots secretion}

MTT assay, a bacterial viability analysis using 3-(4,5-dimethylthiazol-2-yl)-2,5-diphenyl tetrazolium bromide (MTT, sigma), was performed to determine the bacterial biofilm susceptibility to the maggot secretion (Cerca $e t$ al., 2005; Nuryastuti et al. 2009). Bacteria were grown as described above without the maggots secretion. After $24 \mathrm{~h}$ incubation at $37^{\circ} \mathrm{C}$, the bacteria were washed three times with sterile phosphate buffer saline (PBS). The biofilmproducing bacteria were exposed to $100 \mu \mathrm{L}$ maggots secretion, with secretion concentration range $0 \%, 0.31 \%, 0.63 \%, 1.25 \%, 2.5 \%, 5 \%$, $10 \%, 30 \%, 40 \%, 50 \%, 60 \%, 100 \%$ (v/v). The plate were incubated for $2,24,48 \mathrm{~h}$ at $37^{\circ} \mathrm{C}$ after which maggots secretion was removed by washing it twice with $200 \mu \mathrm{L}$ phosphate buffer saline. Briefly, $100 \mu \mathrm{L}$ of prewarmed MTT solution $(5 \mathrm{mg})$ in $10 \mathrm{~mL}$ PBS containing $0.1 \mathrm{~g}$ glucosa and $10 \mu \mathrm{L} 10 \mu \mathrm{M}$ menadion were added to each well. The plate were then incubated at $37^{\circ} \mathrm{C}$ for $30 \mathrm{~min}$ and the MTT solution was removed. Bacteria were then washed with PBS and resuspended in isopropanolol acid (5\% $\mathrm{v} / \mathrm{v} 1 \mathrm{M} \mathrm{HCl}$ in isopropanolol). Finally, the absorbance was measured at $595 \mathrm{~nm}\left(\mathrm{~A}_{595}\right)$. The minimal bactericidal concentration (MBC) was defined as the concentration of maggots ES showing $A_{595}$ values equal to or lower than the control biofilm negative S.epidermidis ATCC12228.

Meanwhile, the planktonic susceptibility testing was done againts maggots secretion on agar plate using Kirby Bauer method (Cappuccino and Sherman, 2001), with some modifications. Briefly, blank disc was filled with the maggots secretion $(10,20,30 \mu \mathrm{L})$. Cefoxitin disk was served as a control. The disk were placed in a space equidistant from each other on Mueller Hinton agar plate and gently touched with a steril forceps. One well in the same plate was made and filled with $100 \mu \mathrm{L}$ maggots secretion. Following the incubation, diameter of each zone of inhibition was measured.

\section{RESULTS AND DISCUSSION Effect of maggots secretion on biofilm formation}

Descriptively, optical density (OD) measurements at 595nm (OD595) was observed using microtiter plate assay. It indicated that biofilm formation of S. epidermidis 294 and 169 were lower than that of $S$. epidermidis ATCC12228 (mean were 0.0637; 0.0665; 0.0839 respectively) for all maggots secretion concentration tested. Meanwhile, S. epidermidis 734 biofilm formation enhanced relatively by low concentration $(<50 \%)$ of maggots secretion (mean was 0.0861) in comparison to $S$. epidermidis ATCC12228 (mean was 0.0839). Relative inhibition of biofilm formation showed in S. epidermidis 734 strain by higher concentration $(>50 \%)$ of maggots secretion (Figure 1). Therefore, to determine the lowest concentration which enhancing biofilm formation, measurement of OD of $S$. epidermidis 734 strain was continued in concentration lower than $10 \%$. In the presence of low concentration $(5 \%)$ of maggots secretion, $S$. epidermidis 734 biofilm formation was extremely induced compared to that of $S$. epidermidis ATCC12228 (Figure 2).

The different effect of maggots excretion/secretion concentration to the different strains descriptively indicated variability between strains. These results was in contrast to the previous study which showed a significant correlation between concentration of secretion of L. sericata maggots with the decrease of $S$. epidermidis biofilm formation. 


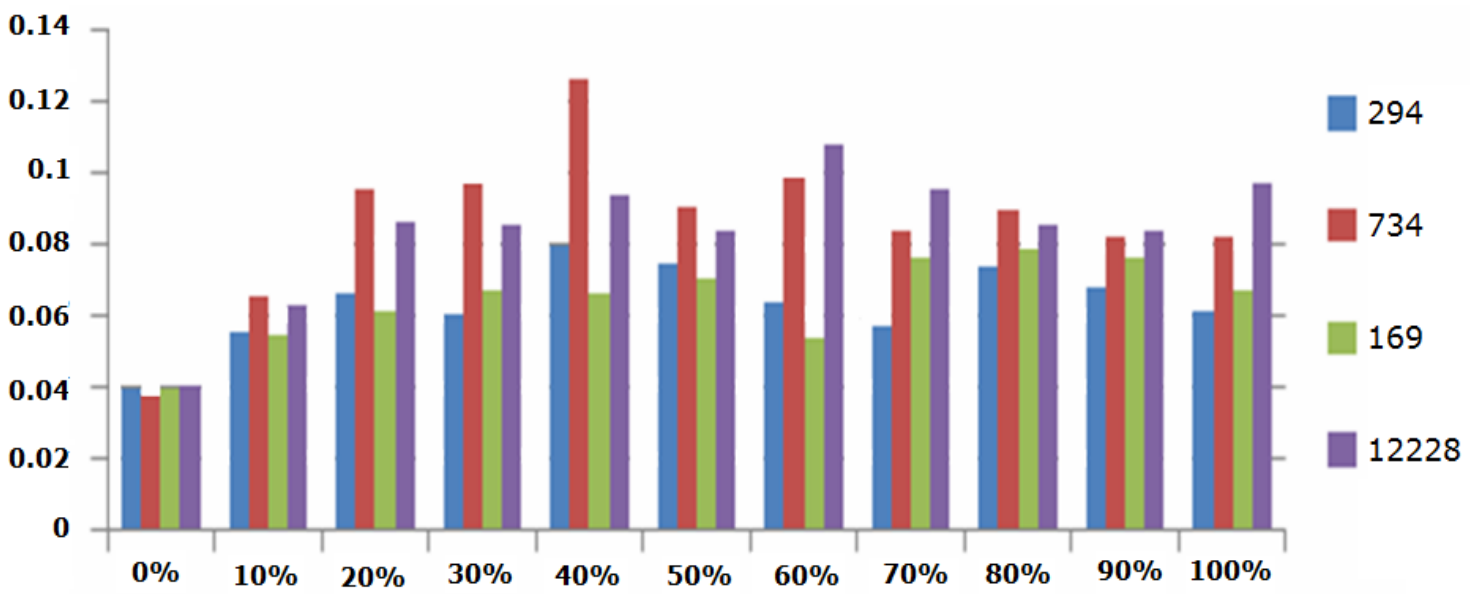

Figure 1. The effect of Cbloroprocta sp. ES directly on S. epidermidis 294, 734, and 169 biofilms formation in comparison with ATCC12228 was observed using microtiter plate biofilm assay with or without maggot ES. Measurement performed three times. Horisontal line indicated concentrations of ES, whereas vertical line indicated biofilm OD.

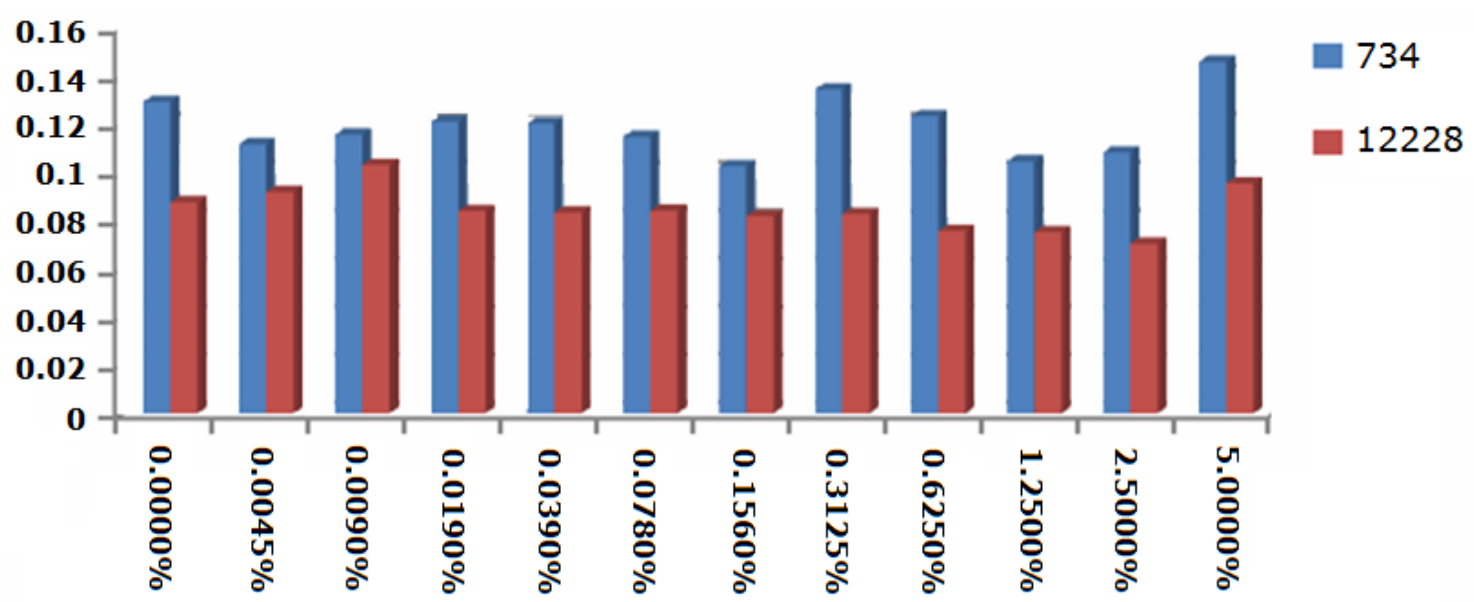

Figure 2. Low concentration (5\%) of maggot ES, S.epidermidis 734 biofilm formation was extremely induced compared to S. epidermidis ATCC12228. It was observed using microtiter plate biofilm assay with or without maggot ES. Measurement performed three times. Horisontal line indicated concentrations of ES, whereas vertical line indicated biofilm OD.

In the other side, the same study showed that the inhibitory activity on biofilm formation not only depends on the concentration, but also on the incubation time (Harris et al., 2009). Meanwhile, the measurement of the effect of maggots secretion to biofilm formation in the present study was based on concentration only.

Naturally the dose response is biphasic, high-dose inhibition and low-dose induction of biofilm formation. Some antimicrobials can be antagonists of biofilm formation at low doses, in the other side they can be agonists at higher doses (Kaplan, 2011). Other possible explanations of this discrepancy were caused by different type of flies used in this study and the amount and type of maggots secretion' components.

\section{IcaA gene expression level}

The expression level of ica $A$ gene in 5\% concentration of maggots secretion was about $1 / 2$ fold than that of without. The result 


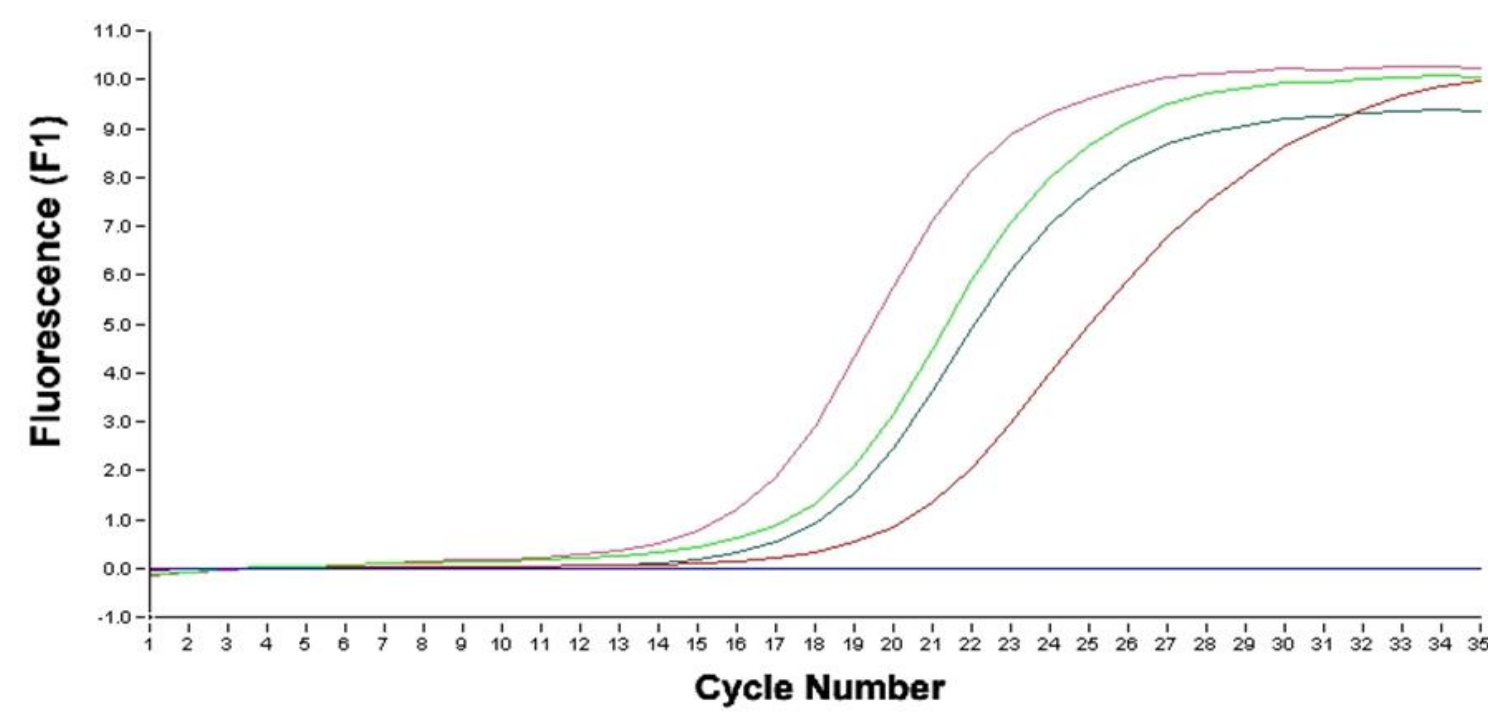

Figure 3. IcaA gene expression level of S.epidermidis 734 with gyrB as the reference. Blueline indicated NTC icaA, Light green line indicated $0 \%$ icaA, dark red line indicated 5\% icaA, Blackline indicated NTCgyrB, Pinkline indicated $0 \%$ gyrB, dark greenline indicated $5 \%$ gyrB

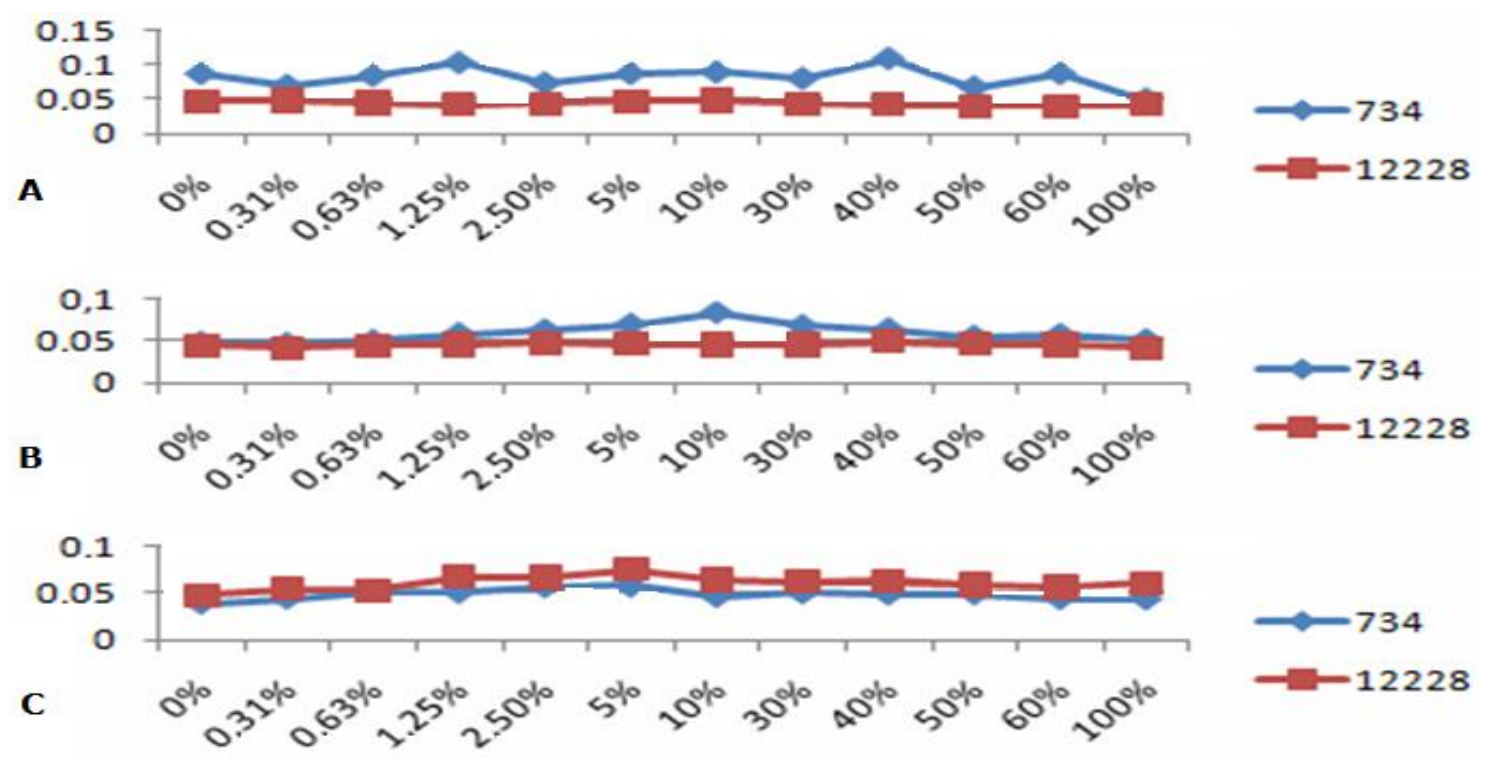

Figure 4. Biofilm susceptibility to maggot ES. A. After incubation time $2 \mathrm{~h}$, B.After incubation time $24 \mathrm{~h}$, C. After incubation time $48 \mathrm{~h}$. Examination in duplo performed using MTT assay. Horisontal line indicated concentrations of ES, whereas vertical line indicated biofilm OD.

demonstrated a significant decrease of the expression level of ica $A$ gene after the addition of $5 \%$ excretion/ secretion compared to that of without (Figure 3) Some previous studies showed that enhanced biofilm formation and ica $A$ gene expression in the addition of low concentrations of antibiotics are based on varied ways of action. The biofilm formation can be induced by some conditions that are potentially toxic for the bacterial cell such as high osmolarity, detergents, urea, ethanol, and oxidative stress (Rachid et al., 2000; Kaplan, 2011). A global response to cell stress plays an important role in the mechanism of conditioninduced biofilm formation of many bacteria (Kaplan, 2011). 
The results of the present study showed that the response of bacteria to low concentrations of maggots secretion was different in phenotype and genotype level. Low concentration of maggots secretion enhanced biofilm formation, contrarily, the same concentration decreased the expression level of icaA gene.

Some possible explanation for the present study were ica genes migth be suppressed in S. epidermidis 734 as a weak biofilm producer and different mechanisms leading to ica expression between different strains in the same species of staphylococci (Kaplan 2011). In addition, the regulation of ica $A$, icaD, icaB, icaC expression is mediated by complex regulatory factors such as global regulatory proteins (SarA and $\sigma B$ ), IcaR and TcaR directly or indirectly. It was also possible that different laboratories (hence different condition) induced biofilm formation and ica expression differently (Cue et al., 2012).

\section{Biofilm susceptibility to maggots secretion}

In order to determine biofilm-bacteria susceptibility to maggots secretion, secretion was added to growing biofilm-bacteria. The culture were then incubated for various durations $(2,24,48 \mathrm{~h})$. Biofilm-bacteria viability was meassured by MTT assay. The results showed that after incubated for 48h, $S$. epidermidis 734 curve (mean $=0.049$ ) was under S. epidermidis ATCC12228 curve (mean $=0.153$ ) consistently, in comparison with incubation time of $2 \mathrm{~h}$ and $24 \mathrm{~h}$ (Figure 4). F test of the multivariat effect of time showed $\mathrm{F}=72.084$, $\mathrm{P}<0.05$. Mean difference (MD) of bacterial viability of $S$. epidermidis 734 compared with $S$. epidermidis ATCC12228 was $-0.011, \mathrm{P}<0.05$. This indicated that bacterial viability of $S$. epidermidis 734 strain was lower than the negative control. It was in accordance to the standard of biofilm minimal bactericidal concentration (MBC). Minimal bactericidal concentration MBC was the concentration of maggots secretion showing $A_{595}$ values equal to or lower than that of the negative control biofilm S. epidermidis ATCC12228 (Nuryastuti et al., 2009). As described previously, MTT assay was used to analyse the effect of secretion of maggots on viability of biofilm-bacteria. Therefore, the result indicated that the control of bacterial biofilm occured after $48 \mathrm{~h}$ in vitro.

In the present study, the eradication of bacterial biofilm was dependent upon the incubation periods but independent upon the concentration of maggots secretion. Meanwhile, the previous study showed that the total number of bacteria in the wells was not significantly changed; demonstrating that secretion of $L$. sericata maggots did not interrupt biofilms by killing bacteria. In vitro killing study discovered that only the highest concentration of maggots secretion $(400 \mu \mathrm{g})$ which reduced the number of viable Staphylococcus aureus after $3 \mathrm{~h}$. Conversely, the maggots secretion did not reduce the number of viable Pseudomonas aeruginosa up to the concentration of $800 \mu \mathrm{g}$ (van-der-Plas et al., 2008).

In the other side, treatment of excretion /secretion of Chloroprocta sp. maggots by KirbyBauer method determined no zone of inhibition formed from all of excretion/ secretion doses (data is not shown). The results revealed that the current doses of secretion did not kill $S$. epidermidis as a planktonic form. Previous study by using RDA assay, the most sensitive in vitro killing assay, determined that $S$. aureus was not killed at the biofilm-effective doses of maggots secretion while $P$. aeruginosa was not killed at all (van-der-Plas et al. 2008).

This in vitro study was a preclinical test for investigating of Chloroprocta sp. maggots secretion effects on biofilm bacteria. Recently, the aim of antibiotics/antimicrobials discovery have concerned on those proteins or processes important for bacterial cell viability (Alksne and Projan, 2000). Therefore, study of antimicrobials that have ability to either improve suppression of biofilm or conventional antibiotics efficacy and their underlying mechanisms lead to the development of novel co-therapeutic agents that can decrease biofilm infections.

\section{CONCLUSSION}

In vitro difference effect of low concentration of secretion of Chloroprocta sp. maggots to phenotype (biofilm formation) and 
genotype (the expression level of ica $A$ gene) of S. epidermidis biofilm showed a possibility that maggots secretion ability to control bacterial biofilm not only with regard to the expression level of icaA gene.

\section{ACKNOWLEDGEMENT}

Thanks to Ir. Mulyono MSi for providing sterile Chloroprocta sp. Maggots; to Diponegoro University-Kariadi Hospital; to Gadjah Mada University for the laboratory facilities, to Risbin Iptekdok 2013; and to Soedirman University for support.

\section{REFERENCES}

Alksne LE., and Projan SJ. 2000. "Bacterial virulence as a target for antimicrobial chemotherapy" Pharmaceutical biotechnology 11: 625-636.

Arora S., Lim CS. and Baptista C. 2010. "Antibacterial activity of Lucilia cuprina maggots extracts and its extraction tehniques." I I Integrative Biol 9 No 1: 4348.

Cafiso V., Bertuccio T., Santagatf M., Campanile F., Amicosante G., Perilli M., Selan L., Artini M., Nicoletti' G. and Stefani S. 2004. "Presence of the ica operon in clinical isolates of Staphylococcus epidermidis and its role in biofilm production." Clin Microbiol Infect 10: 1081-1088.

Cappuccino JG. and Sherman N. 2001. "Microbiology A Laboratory Manual." Sixth Edition: 264-266.

Cerca N., Martins S., Cerca F., Jefferson K., Pier G., Oliveira R. and Azeredo J. 2005. "Comparative assessment of antibiotic susceptibility of coagulase-negative staphylococci in biofilm versus planktonic culture as assesed by bacterial enumeration or rapid XTT colorimetry." J Antimicrob Chemother 56: 331-336.

Cue D., Lei MG. and Chia Y Lee 2012. "Genetic regulation of the intercellular adhesion locus in staphylococci." Frontiers in Celullar And Infection Microbiology 2: 113.
Davies D. 2003. "Understanding biofilm resistance to antibacterial agents " Nature Reviews Drug Discovery 2.

Harris LG., Bexfield A., Nigam Y., Rohde H., Ratcliffe NA. and Mack D. 2009. "Disruption of Staphylococcus epidermidis biofilms by medicinal maggots Lucilia sericata excretions/ secretions." I J Artificial Organs Vol. 32 / no. 9 555-564.

Kaplan, JB. (2011). "Antibiotic-induced biofilm formation." Int J Artif Organs 34(9) 737751.

Mack D., Fischer W., Krokotsch A., Leopold K., Hartmann R. and Egge H. 1996. "The intercellular adhesin involved in biofilm accumulation of Staphylococcus epidermidis in hemaglutination." Infect immmun 67 1004-1008.

Merrit JH., Kadouri DE. and O’Toole GA. 2011. "Growing and Analyzing Static Biofilms " Current Protocols in Microbiology 22: 1B11-11B118.

Nuryastuti T., Mei HCvd., Busscher HJ., Iravati S, Aman AT. and Krom BP. 2009. "Effect of cinnamon oil on icaAexpression and biofilm formation by Staphylococcus epidermidis." Applied and Environmental Microbiology 75: 6850-6855.

O'Gara JP. and H. Humphreys 2001. "Staphylococcus epidermidis biofilms: importance and implications." J Med Microbiol 50: 582-587.

Rachid S., Cho S., Ohlsen K., Hacker J. and Ziebuhr W. 2000. "Induction of Staphylococcus epidermidis biofilm formation by environmental factors: the possible involvement of the alternative transcription factor SigB." In Emo L. .dy, Blum-Oehler G., Hacker J., and Pal T. (ed.), Genes and proteins underlying microbial urinary tract virulence. Plenum Press, New York, N.Y: 159-166.

Rachid S., Ohlsen K., Witte W., Hacker Jr. and Ziebuhr W. 2000. "Effect of Subinhibitory Antibiotic Concentrations on Polysaccharide Intercellular Adhesin Expression in Biofilm-Forming $S$. 
Dwi Utami Anjarwati

epidermidis. Antimicrobial Agents And Chemotherapy 44 (Dec. 2000): 3357-3363.

Rupp M. and Archer G. 1994. "Coagulasenegative staphylococci: pathogens associated with medical progress." Clin Infect Dis 19 231-245.
van-der-Plas MJA., Jukema GN., Wail SW., Dogterom-Ballering HCM. et al., 2008. "Maggots excretions/secretions are differentially effective against biofilms of Staphylococcus aureus and Pseudomonas aeruginosa J. Antimicrobial Chemotherapy 61: 117-122. 